\title{
Left Ventricular Inflow Velocity Pattern in Patients With Symptomatic Premature Ventricular Contraction
}

\author{
Satoshi Takahashi, MD; Takanao Mine, MD, PhD; Kenki Ashida, MD; \\ Hideyuki Kishima, MD, PhD; Tohru Masuyama, MD, PhD; Masaharu Ishihara, MD, PhD
}

\begin{abstract}
Background: Because premature ventricular contractions (PVCs) are one of the most common arrhythmias, but with unclear causative mechanisms, we studied the hemodynamic features that can cause symptomatic PVCs.
\end{abstract}

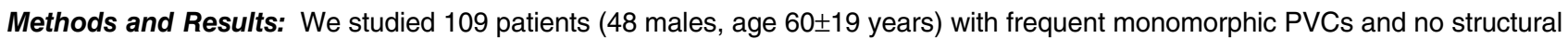
heart disease. The left ventricular inflow diastolic filling velocity was recorded by transthoracic echocardiography (TTE) at the time of PVCs in all patients. We assessed the PVC E wave flow (E wave velocityxduration at PVC). A total of 38 patients (35\%) had PVCrelated symptoms (19 palpitations, 12 pulse deficit, 6 shortness of breath, 6 malaise, 1 syncope). These patients showed reduced PVC E wave flow ( $9.3 \pm 6.0$ vs. $14.6 \pm 6.5 \mathrm{~cm}, \mathrm{P}<0.0001)$, and reduced $\mathrm{PVC}$ stroke volume $(20.5 \pm 10.8 \mathrm{vs} .29 .9 \pm 17.2 \mathrm{~mL}, \mathrm{P}=0.0030)$. In the multivariate analysis, only reduced PVC E wave flow was independently associated with $P V C$-related symptoms ( $P=0.00349$, odds ratio: 1.134029, each $1.0 \mathrm{~cm}$ increase in PVC E wave flow, 95\% confidence interval: 1.040726-1.247544).
\end{abstract}

Conclusions: Decreased E wave flow at the time of PVC was independently related with PVC-related symptoms in patients with PVCs. The LV contraction at the time of inadequate filling might be a cause of PVC-related symptoms.

Key Words: Hemodynamics; Left ventricular inflow; Premature ventricular contractions (PVCs); PVC-related symptoms; Stroke volume

$\mathbf{P}$ remature ventricular contractions (PVCs) are a common arrhythmia, even in people without structural heart disease, and has been reported at an incidence rate of approximately $1 \%$ on standard 12 -lead ECGs and $40-75 \%$ on routine $24-\mathrm{h}$ Holter ECG. ${ }^{\mathbf{1}, 2}$ PVCs in a structurally normal heart are almost idiopathic, but multiform PVCs, high PVC burden, or the presence of non-sustained ventricular tachycardia (VT) are associated with inverse clinical outcomes such as death, heart failure and cardiovascular hospitalization. ${ }^{3-5}$ Many previous reports show that PVCs can develop into cardiomyopathy and that risk factors include PVC frequency, PVC origin, short PVC coupling interval (CI), and VT. ${ }^{6-9}$ Some patients have symptoms that were seemingly associated with PVCs and require treatment such as antiarrhythmic drugs ${ }^{10-12}$ or catheter ablation, ${ }^{13-15}$ which have been reported as effective. PVC-related symptoms include pulse deficit, palpitations, shortness of breath, malaise and syncope. Yet no explicit relationship between the presence of symptoms and the frequency of PVCs has been observed. ${ }^{16}$ The mechanism of symptomatic PVCs is still unknown, although the PVC CI is associated with symptoms. ${ }^{17}$ There have been few reports on the relationship between PVCs and these symptoms, and the cause of symptomatic PVCs remains unclear. Therefore, we investigated the hemodynamic features that could cause symptomatic PVCs.

\begin{abstract}
Methods
Patients

We enrolled 189 consecutive patients with frequent monomorphic PVCs on standard 12-lead or 24-h Holter ECG who visited Hyogo College of Medicine for examination of PVCs between November, 2016 and January, 2018. We defined frequent PVC when $\geq 2$ beats of PVC were recorded on 12-lead ECG during a 10 -s period more than twice. Of the patients, 27 who had structural heart disease $(11$ cases of ischemic heart disease, 2 of hypertrophic cardiomyopathy, 4 of hypertensive heart disease, 1 case each of dilated cardiomyopathy and severe aortic valve regurgitation, 5 other cases) or rhythm abnormality ( 3 cases of atrial fibrillation, 2 cases of pacemaker rhythm) were excluded. Among the remaining 162 patients, 1 case of bigeminy of PVCs, one of unstable interval of preceding $\mathrm{R}$ wave and $\mathrm{PVC}$, and 7 cases of an unclear relationship between PVCs and symptoms were also excluded. Patients with polymorphic PVCs on standard 12-lead or 24-h Holter ECG were not included. Another 44 cases of patients who did not have PVCs recorded during echocardiography were also excluded, and the remaining 109 patients were studied.

All patients underwent standard 12-lead ECG, 24-h Holter ECG and echocardiography. Blood samples for atrial natriuretic peptide (ANP) and B-type natriuretic pep-
\end{abstract}

Received July 4, 2019; revised manuscript received October 9, 2019; accepted October 29, 2019; J-STAGE Advance Publication released online December 4, 2019 Time for primary review: 26 days

Cardiovascular Division, Department of Internal Medicine, Hyogo College of Medicine, Nishinomiya, Japan

Mailing address: Takanao Mine, MD, Cardiovascular Division, Department of Internal Medicine, Hyogo College of Medicine, 1-1 Mukogawa-cho, Nishinomiya 663-8501, Japan. E-mail: mine@hyo-med.ac.jp

ISSN-1346-9843 All rights are reserved to the Japanese Circulation Society. For permissions, please e-mail: cj@j-circ.or.jp 


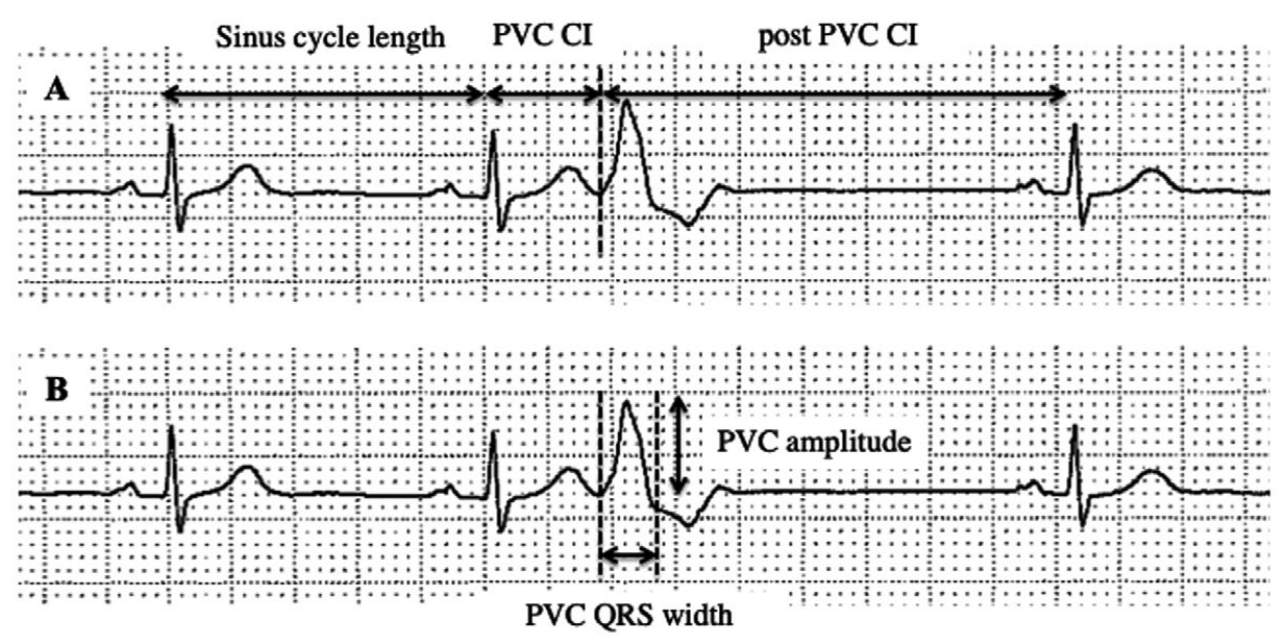

Figure 1. Examples of the parameters measured on ECG. (A) Sinus cycle length (ms): the interval of the sinus R wave immediately before a PVC; PVC coupling interval $(\mathrm{Cl})(\mathrm{ms})$ : the interval from onset of the previous sinus R wave to the onset of a PVC; post-PVC $\mathrm{Cl}(\mathrm{ms})$ : the interval from the onset of a PVC to the previous sinus R wave. (B) PVC amplitude (mV): the highest amplitude of the PVC R wave in a precordial lead; PVC QRS width (ms): the average value from the onset of the $Q$ or R wave to end of the $S$ wave PVC QRS in all 12 leads. PVC, premature ventricular contraction.

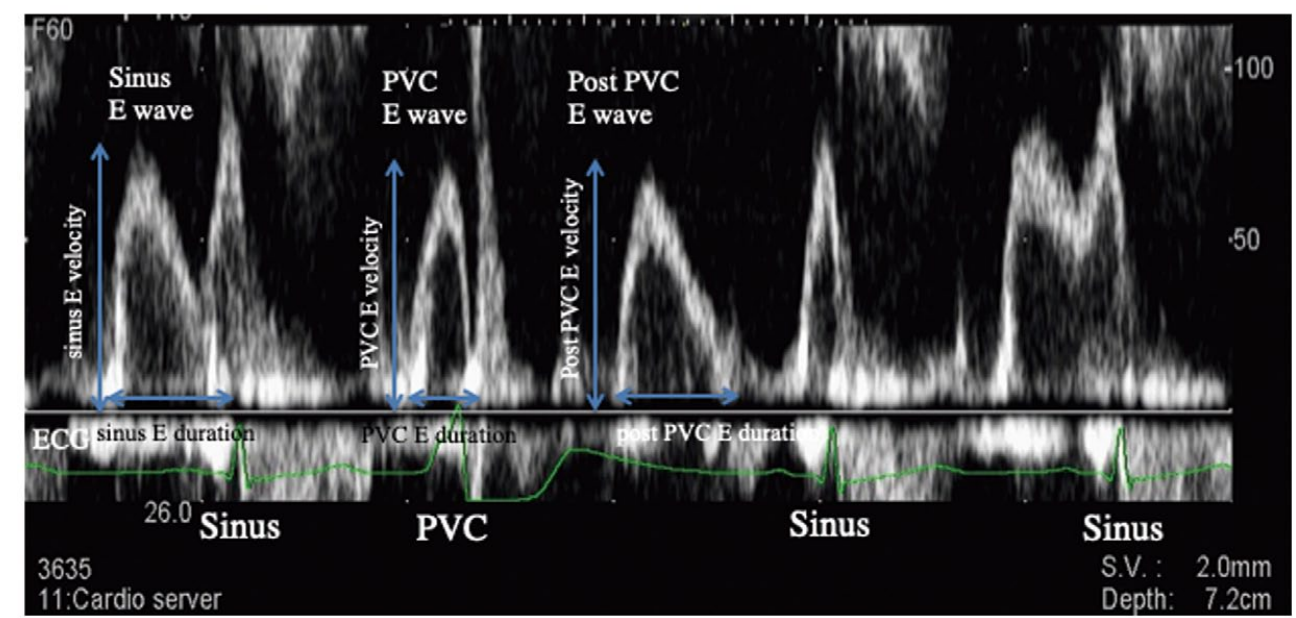

Figure 2. Left ventricular (LV) inflow on echocardiography. During the sinus diastolic phase, the initial LV inflow was defined as "sinus E wave", and the value obtained by multiplying the maximum sinus E wave velocity and duration was defined as the "sinus E wave flow". When z PVC occurred in the middle of the E wave in the sinus diastolic phase, this E wave was defined as the "PVC E wave". During the PVC diastolic phase, LV inflow was defined as "post-PVC E wave". These parameters were calculated as: sinus $E$ wave flow=(sinus $E$ velocity $) \times($ sinus $E$ duration); PVC E wave flow=(PVC E velocity $) \times(P V C$ E duration); post $P V C$ E wave flow $=($ post $-P V C$ E velocity $) \times($ post $-P V C$ E duration $) . P V C$, premature ventricular contraction.

tide (BNP) were obtained. Symptoms were evaluated by reviewing the cardiology records. When the patients had palpitations, pulse deficit, shortness of breath, malaise or syncope. these symptoms were defined as PVC related. The research protocol was approved by the appointed local ethics committee.

\section{Electrocardiography}

For all patients, the standard 12-lead ECG was recorded at sweep speed of $25 \mathrm{~mm} / \mathrm{s}$. The QRS width of the PVC was measured from the QRS onset point to the $S$ wave endpoint. PVC amplitude was defined as the highest amplitude of the $\mathrm{R}$ wave in the precordial lead. We also investigated PVC morphology and axis. PVC morphology was defined as right bundle branch block pattern if QRS was positive in lead V1 or as left bundle branch block pattern for negative QRS in V1. The type of PVC axis was divided into inferior or superior. PVCs with positive QRS in inferior 


\begin{tabular}{|c|c|c|c|}
\hline & $\begin{array}{l}\text { With symptoms } \\
\qquad(n=38)\end{array}$ & $\begin{array}{l}\text { Without symptoms } \\
\qquad(n=71)\end{array}$ & $P$ value \\
\hline Age (years) & $62 \pm 18$ & $59 \pm 20$ & 0.4204 \\
\hline Male sex & $17(44 \%)$ & $44(62 \%)$ & 0.1062 \\
\hline Body mass index $\left(\mathrm{kg} / \mathrm{m}^{2}\right)$ & $23.8 \pm 4.3$ & $23.0 \pm 4.7$ & 0.3730 \\
\hline Dyslipidemia & $16(42 \%)$ & $23(32 \%)$ & 0.4020 \\
\hline Hypertension & $20(53 \%)$ & $35(49 \%)$ & 0.8413 \\
\hline Diabetes mellitus & $11(29 \%)$ & $19(27 \%)$ & 0.8249 \\
\hline Hemoglobin (g/dL) & $13.5 \pm 2.2$ & $13.2 \pm 1.9$ & 0.5116 \\
\hline Hematocrit (\%) & $41.0 \pm 6.2$ & $38.9 \pm 8.0$ & 0.2272 \\
\hline Serum creatinine $(\mathrm{mg} / \mathrm{dL})$ & $0.9 \pm 0.7$ & $1.2 \pm 1.8$ & 0.4696 \\
\hline B-type natriuretic peptide $(\mathrm{pg} / \mathrm{mL})$ & $76 \pm 88$ & $90 \pm 129$ & 0.5607 \\
\hline Atrial natriuretic peptide $(\mathrm{pg} / \mathrm{mL})$ & $54 \pm 52$ & $72 \pm 79$ & 0.2179 \\
\hline \multicolumn{4}{|l|}{ Medications } \\
\hline$\beta$-blocker & $8(21 \%)$ & $15(21 \%)$ & 1.0000 \\
\hline Diuretic & $3(8 \%)$ & $6(8 \%)$ & 1.0000 \\
\hline
\end{tabular}

\begin{tabular}{|lccc|}
\hline Table 2. 12-Lead ECG and Holter ECG Findings & & \\
& $\begin{array}{c}\text { With symptoms } \\
(\mathbf{n = 3 8 )}\end{array}$ & $\begin{array}{c}\text { Without symptoms } \\
\mathbf{( n = 7 1 )}\end{array}$ & P value \\
12-lead ECG & & & \\
PVC morphology & & & \\
Inferior axis (\%) & $29(76 \%)$ & $60(85 \%)$ & 0.3093 \\
LBBB pattern (\%) & $21(55 \%)$ & $43(61 \%)$ & 0.6841 \\
Sinus cycle length (ms) & $923 \pm 187$ & $902 \pm 178$ & 0.5652 \\
PVC Cl (ms) & $487 \pm 86$ & $510 \pm 85$ & 0.1915 \\
PVC Cl ratio (\%) & $54 \pm 11$ & $58 \pm 11$ & 0.0888 \\
Post-PVC Cl (ms) & $1,177 \pm 330$ & $1,145 \pm 310$ & 0.6247 \\
Post-PVC Cl ratio & $128 \pm 27$ & $128 \pm 28$ & 0.9734 \\
PVC duration & $141 \pm 38$ & $136 \pm 46$ & 0.5507 \\
PVC amplitude & $1.9 \pm 0.6$ & $2.1 \pm 0.8$ & 0.1889 \\
Holter ECG & & & \\
No. of PVCs (beats) & $10,557 \pm 11,553$ & $9,026 \pm 9,452$ & 0.4580 \\
PVC burden (\%) & $9.8 \pm 10.3$ & $8.9 \pm 9.1$ & 0.6636 \\
\hline
\end{tabular}

$\mathrm{Cl}$, coupling interval; PVC, premature ventricular contraction.

leads were defined as inferior axis type, and those with negative QRS in inferior leads was defined as superior axis type. The EFS-8800 Data Management System ${ }^{\circledR}$ (Fukuda Denshi, Tokyo, Japan) was used to measure PVC width and amplitude.

The QRS interval of the sinus beats just before the PVC was defined as "sinus cycle length". The interval from the onset of the $\mathrm{R}$ wave of the sinus beat immediately before the PVC to the onset of the R wave of the PVC was defined as the PVCCI, and the PVC "CI ratio" was defined as PVC $\mathrm{CI} /$ sinus cycle length (Figure 1). ${ }^{17}$ Similarly, the interval from the onset of the R wave of the PVC to the onset of the $\mathrm{R}$ wave of the next sinus beat was defined as "post-PVC CI", and the "post-PVC CI ratio" was defined as post-PVC $\mathrm{CI} /$ sinus cycle length.

\section{Echocardiography}

The echocardiographic examination was performed using iE33 (Philips Medical Systems, Andover, MA, USA) or Aplio 300 (Toshiba Medical Systems, Tokyo, Japan) with a 3-MHz transducer probe. All parameters on echocar- diography were extracted by the off-line analysis station or on-line analysis tool attached to the above equipment with the clinical information blinded. Parameters such as left ventricular diastolic dimension (LVDd), left ventricular ejection fraction (LVEF) using the Teicholz formula, E wave, A wave velocity, E/A, deceleration time (DCT), E' and A' were assessed in sinus rhythm based on the recommendations of the American Society of Echocardiography. ${ }^{18}$

In all patients, the patterns of $\mathrm{LV}$ inflow and $\mathrm{LV}$ outflow at the time of PVC, at the sinus beat just after PVC and during continuous sinus beats were evaluated. The maximum velocity and the wave duration of the $\mathrm{LV}$ inflow wave were measured during the LV diastolic phase following continuous sinus beats, and the value of multiplying the maximum velocity by the wave duration of the LV inflow wave was defined as "sinus E wave flow" (Figure 2). The E wave at the time of PVC was defined as "PVC E wave", and the value of multiplying the maximum velocity by the duration of PVC E wave was defined as "PVC E wave flow". The E wave after the time of PVC was defined as "post-PVC E wave", and the value of multiplying the max- 


\begin{tabular}{|c|c|c|c|}
\hline & $\begin{array}{l}\text { With symptoms } \\
(n=38)\end{array}$ & $\begin{array}{l}\text { Without symptoms } \\
\qquad(\mathrm{n}=71)\end{array}$ & $P$ value \\
\hline LVDd (mm) & $49.2 \pm 5.4$ & $49.6 \pm 5.5$ & 0.7022 \\
\hline LVEF (\%) & $64.5 \pm 9.4$ & $64.9 \pm 7.3$ & 0.7984 \\
\hline LV mass $(\mathrm{g})$ & $132 \pm 37$ & $140 \pm 36$ & 0.3223 \\
\hline LV mas index $\left(\mathrm{g} / \mathrm{m}^{2}\right)$ & $78 \pm 17$ & $83 \pm 15$ & 0.1189 \\
\hline Relative wall thickness & $0.32 \pm 0.04$ & $0.33 \pm 0.05$ & 0.5911 \\
\hline LA diameter (mm) & $38.3 \pm 7.1$ & $36.5 \pm 7.0$ & 0.2104 \\
\hline LA volume index $\left(\mathrm{mL} / \mathrm{m}^{2}\right)$ & $32.4 \pm 13.4$ & $31.9 \pm 9.9$ & 0.8234 \\
\hline E wave $(\mathrm{cm} / \mathrm{s})$ & $70.9 \pm 18.2$ & $68.1 \pm 17.7$ & 0.4414 \\
\hline A wave $(\mathrm{cm} / \mathrm{s})$ & $73.1 \pm 22.6$ & $73.5 \pm 26.7$ & 0.9414 \\
\hline $\mathrm{E} / \mathrm{A}$ ratio & $1.1 \pm 0.5$ & $1.2 \pm 1.2$ & 0.4279 \\
\hline Deceleration time (ms) & $199 \pm 48$ & $194 \pm 49$ & 0.6098 \\
\hline E' wave $(\mathrm{cm} / \mathrm{s})$ & $6.9 \pm 2.7$ & $7.2 \pm 3.1$ & 0.6419 \\
\hline$A^{\prime}$ wave $(\mathrm{cm} / \mathrm{s})$ & $9.3 \pm 2.3$ & $8.7 \pm 2.3$ & 0.2547 \\
\hline E/E' ratio & $11.0 \pm 3.7$ & $10.9 \pm 4.8$ & 0.9097 \\
\hline Sinus $E$ wave flow $(\mathrm{cm})$ & $20.7 \pm 7.0$ & $20.0 \pm 5.0$ & 0.5239 \\
\hline PVC E wave flow $(\mathrm{cm})$ & $9.3 \pm 6.0$ & $14.6 \pm 6.5$ & $<0.0001$ \\
\hline Post-PVC E wave flow (cm) & $20.1 \pm 7.8$ & $19.1 \pm 6.6$ & 0.5086 \\
\hline Sinus SV (mL) & $71.1 \pm 14.6$ & $71.9 \pm 19.3$ & 0.8112 \\
\hline PVC SV (mL) & $20.5 \pm 10.8$ & $29.9 \pm 17.2$ & 0.0030 \\
\hline Post-PVC SV (mL) & $80.6 \pm 20.3$ & $81.5 \pm 23.5$ & 0.8471 \\
\hline
\end{tabular}

LA, left atrial; LVDd, left ventricular end-diastolic diameter; LVEF, left ventricular ejection fraction; PVC, premature ventricular contraction; SV, stroke volume.

imum velocity by the duration of the post-PVC E wave was defined as "post-PVC E wave flow" (Figure 2). Stroke volume (SV) were measured using the velocity time integral during continuous sinus beats, at the time of PVC, at the sinus beat just after PVC and defined as "sinus SV", "PVC SV" and "post-PVC SV", respectively.

\section{Statistical Analysis}

Continuous variables are expressed as mean \pm 1 standard deviation and compared using the Student's t-test. Differences between categorical variables were evaluated with $X^{2}$ analysis. The strength of bivariate associations between PVC-related symptoms and potential predictors were measured using odds ratio (OR). Parameters that were associated with $\mathrm{P}<0.05$ in bivariate analyses were entered in a logistic regression analysis to assess whether the individual variables predicted $\mathrm{PVC}$-related symptoms. $\mathrm{P}<0.05$ was considered statistically significant in the logistic regression model. All analyses were performed with JMP version 12.0 software (SAS Institute, Cary, NC, USA).

\section{Results}

\section{Patients' Characteristics}

Of the 109 patients (48 females, age $60 \pm 19$ years-old) enrolled in this study, symptoms were observed in $38(35 \%)$. PVC-related symptoms comprised 19 cases of palpitations $(50 \%), 12$ cases of pulse deficit (32\%), 6 cases of shortness of breath $(16 \%), 6$ cases of malaise $(16 \%)$ and 1 case of syncope $(3 \%)$, and some of them had more than 1 symptom. There were no significant differences in age, sex, body mass index (BMI), ANP or BNP levels, and the dosage of $\beta$-blockers between patients with and without symptoms (Table 1).

\section{2-Lead ECG and Holter ECG}

There were no differences in PVC width $(139 \pm 42$ vs. $137 \pm 44 \mathrm{~ms})$, amplitude $(1.9 \pm 0.7$ vs. $2.0 \pm 0.8 \mathrm{mV})$ or morphology between the groups with and without symptoms (Table 2). PVC CI ( $487 \pm 86$ vs. $510 \pm 85 \mathrm{~ms})$, PVC CI ratio $(54 \pm 11 \%$ vs. $58 \pm 11 \%)$, post-PVC CI $(1,177 \pm 330$ vs. $1,145 \pm$ $310 \mathrm{~ms})$ and post-PVC CI ratio (128 $\pm 27 \%$ vs. $128 \pm 28 \%$ ) in patients with symptoms did not differ from those without. There were no differences in the number of PVCs per day or the PVC burden measured by Holter ECG between the groups with and without the symptoms. The patients with palpitations did not differ from the patients with other symptoms in the measurement values on 12-lead ECG and Holter ECG.

\section{Echocardiography}

LVDd, LVEF, left atrial diameter, E wave, A wave, E/A ratio, DCT, E' wave, A' wave, E/ E' in the patients with symptoms did not differ from the patients without symptoms (Table 3). All patients with LV hypertrophy were excluded, and there was no difference between the patients with symptomatic and non-symptomatic groups in LV mass, LV mass index, and relative wall thickness. There were no patients with moderate or severe mitral regurgitation. The PVC E wave flow in the patients with symptoms was reduced compared with the patients without symptoms $(9.3 \pm 6.0$ vs. $14.6 \pm 6.5 \mathrm{~cm}, \mathrm{P}<0.0001)$. However, there were no differences in sinus $\mathrm{E}$ wave flow $(20.7 \pm 7.0$ vs. $20.0 \pm 5.0 \mathrm{~cm})$ and post-PVC E wave flow $(20.1 \pm 7.8$ vs. $19.1 \pm 6.6 \mathrm{~cm}$ ) between the groups with and without the symptoms (Table 3). Figure 3 shows representative cases of LV inflow pattern. A 65-year-old male with palpitations had reduced PVC E wave flow $(4.21 \mathrm{~cm})$, and a 47 -year-old female without symptoms presented a PVC E wave flow $(23.87 \mathrm{~cm})$ similar to sinus $\mathrm{E}$ wave flow. 

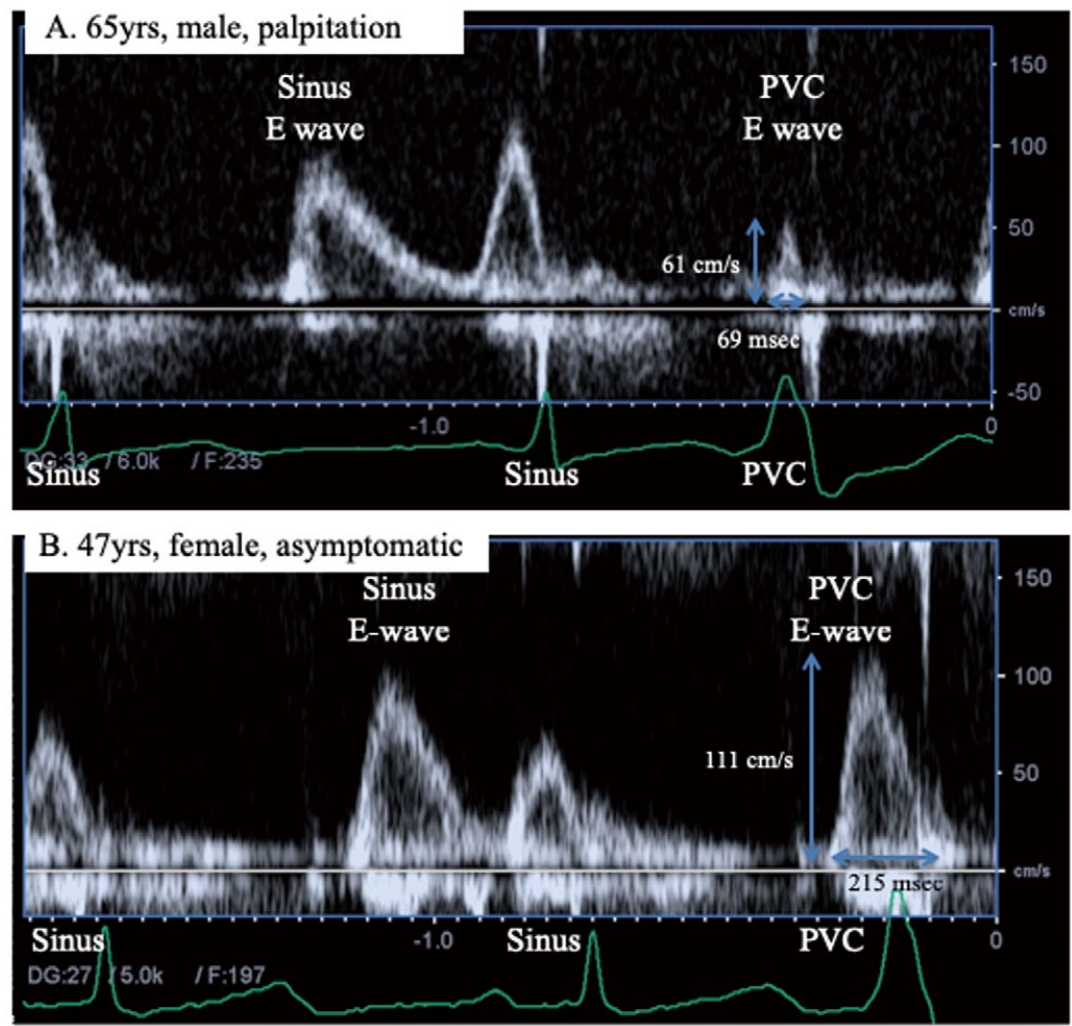

Figure 3. Two examples of LV inflow wave at echocardiogram. The top figure $(\mathbf{A})$ shows the LV inflow wave of a 65-year-old male, symptomatic patient. The PVC E wave velocity was $61 \mathrm{~cm} / \mathrm{s}$, and duration $69 \mathrm{~ms}$. The PVC E wave flow wave was calculated as $4.21 \mathrm{~cm}$. The bottom figure (B) shows the LV inflow wave of a 47 -year-old female, asymptomatic patient. The PVC E wave velocity was $111 \mathrm{~cm} / \mathrm{s}$, and duration $215 \mathrm{~ms}$. The PVC E wave flow wave was calculated as $23.87 \mathrm{~cm}$.

\begin{tabular}{|c|c|c|c|}
\hline & \multirow{2}{*}{$\begin{array}{c}\text { Univariate analysis } \\
\mathrm{P} \text { value }\end{array}$} & \multicolumn{2}{|c|}{ Multivariate analysis } \\
\hline & & $P$ value & OR (95\% Cl) \\
\hline PVC E wave flow $(\mathrm{cm})$ & $<0.0001$ & 0.00349 & $1.134029^{*}(1.040726-1.247544)$ \\
\hline PVC SV (mL) & 0.0013 & 0.27440 & $1.020960(0.984595-1.063687)$ \\
\hline
\end{tabular}

${ }^{*} \mathrm{OR}$ for each $1.0 \mathrm{~cm}$ increase in PVC E wave flow. Cl, confidence interval; OR, odds ratio; PVC, premature ventricular contraction.

The PVC SV of the patients with symptoms was decreased compared with the patients without symptoms ( $20.5 \pm 10.8$ vs. $29.9 \pm 17.2 \mathrm{~mL}, \mathrm{P}=0.0030)$, and there were no differences in sinus SV $(71.1 \pm 14.6$ vs. $71.9 \pm 19.3 \mathrm{~mL})$ and post-PVC SV $(80.6 \pm 20.3$ vs. $81.5 \pm 23.5 \mathrm{~mL})$ between the groups with and without the symptoms (Table 3). The patients with palpitations did not differ from the patients with other symptoms in the measurement values on echocardiography.

\section{Multivariate Cox Regression Analysis}

In the multivariate analysis among PVC E wave flow and PVC SV, only PVC E wave flow was independently associated with symptoms $(\mathrm{P}=0.00349, \mathrm{OR} 1.134029$ each $1.0 \mathrm{~cm}$ increase in PVC E wave flow, 95\% confidence interval 1.040726-1.257544) (Table 4). Receiver-operating characteristics curve analysis demonstrated that a PVC E wave flow cutoff value of $8.1 \mathrm{~cm}$ separated patients with and without PVC-related symptoms (area under the curve 0.74 , sensitivity 0.58; specificity 0.86) (Figure 4).

\section{Intra- and Interobserver Reliability}

To evaluate the intra- and interobserver reliability for PVC $\mathrm{CI}$ index and PVC E wave flow, 3 different PVC beats for PVC CI, and 2 different PVC beats for PVC E wave flow were independently measured by 2 cardiologists. Intraclass correlation coefficients (ICC) were used to describe interand intra-observer reliability. The ICC for intra-observer reliability for the PVC CI index was 0.91 . The ICC for interobserver reliability was 0.99 . As with the PVC CI index, the ICC for intra- and interobserver reliability for the PVC E wave flow was 0.92 and 0.98 , respectively, which was a good correlation.

\section{Discussion}

In clinical practice, there are patients who are asymptomatic despite frequent PVCs, and patients who suffer from deteriorating quality of life with few PVCs. However, the cause of PVC-related symptoms is unclear. In our study, we scrutinized the hemodynamic features related to symptom- 
atic PVCs in 109 consecutive patients with no structural heart disease. Reduced LV inflow in the diastolic phase was associated with PVC symptoms. Chronic cough, difficulty in swallowing, intermittent claudication, eye flashes and stroke-like symptoms have been previously reported as symptoms associated with PVC, ${ }^{19-21}$ but not in our study subjects. The symptoms related to PVC that were examined in this study were palpitations, pulse deficit, shortness of breath, malaise and syncope. In 38 (35\%) cases, PVCrelated symptoms were observed, with 19 cases $(50 \%)$ of palpitations, 12 cases $(32 \%)$ of pulse deficit, 6 cases $(16 \%)$ of shortness of breath, 6 cases $(16 \%)$ of malaise and 1 case (3\%) of syncope. Furthermore, Park et al indicated that the PVC CI ratio was related to PVC-related symptoms. They investigated the predictors of symptoms (palpitations and "dropped beats") in patients with idiopathic PVCs originating from the outflow tract, and a PVC CI ratio $>50 \%$ was related to the appearance of symptoms. ${ }^{17}$ In our study, a short PVC CI ratio was not associated with symptoms, which was different from the results of Park et al. Their study included cases of decreased left ventricular contractility, so the difference could be related to the characteristics of the population analyzed, with a high rate $(72 \%)$ of symptomatic PVC patients in the study by Park et al. Similar to our study, Contijoch et al examined the hemodynamic changes during PVC using cardiac MRI and they reported that cardiac output decreased significantly with extra systole. ${ }^{22}$ However, they did not mention any association with PVC symptoms.

\section{Mechanism of PVC-Related Symptoms}

In previous reports, decreased PVC SV could be involved in symptoms. ${ }^{22-24}$ The mechanism of the hemodynamic changes caused by PVCs has been suggested as (1) a decrease in PVC SV, (2) insufficient LV filling because of the short diastolic phase immediately before the appearance of a PVC, and (3) an increase in SV in the sinus beat following PVC caused by a decrease in LV filling at the time of the PVC.

In our result, only decreased PVC E wave flow was independently associated with PVC-related symptoms. When PVC occurs in the early diastolic phase, the mitral valve closes and the LV inflow is decreased. As a result, the volume overload of the left atrium increases, the left atrial pressure increases, and retrograde blood flow to the pulmonary vein (PV flow reversal) increases. We anticipated that when the PVC E wave flow decreased, LV inflow would increase to compensate during the sinus beat following the PVC, but there was no significant difference in the postPVC E wave flow between the patients with and without symptoms. Cohn et $\mathrm{al}^{24}$ reported that $\mathrm{SV}$ at the sinus beat following a PVC demonstrated only an average increase of $8 \mathrm{~mL}$ compared with the SV of the sinus cycle. They concluded that the phenomenon of postextrasystolic potentiation plays a minor role in augmenting SV. We consider that because there is not a compensatory increase in the inflow volume to the LV, SV does not increase according to the Frank-Starling law. We hypothesize that the reason for the reduced increase in the inflow to the $\mathrm{LV}$ is the impaired diastolic function of the LV most noticeably during the PVC. Excessive volume load in the left atrium and PV results in increased left atrial pressure and pulmonary capillary pressure and the possibility of symptoms appearing. Laurent et $\mathrm{al}^{\mathbf{2 5}}$ reported an association between symptoms in supraventricular tachycardia and left atrial pressure and

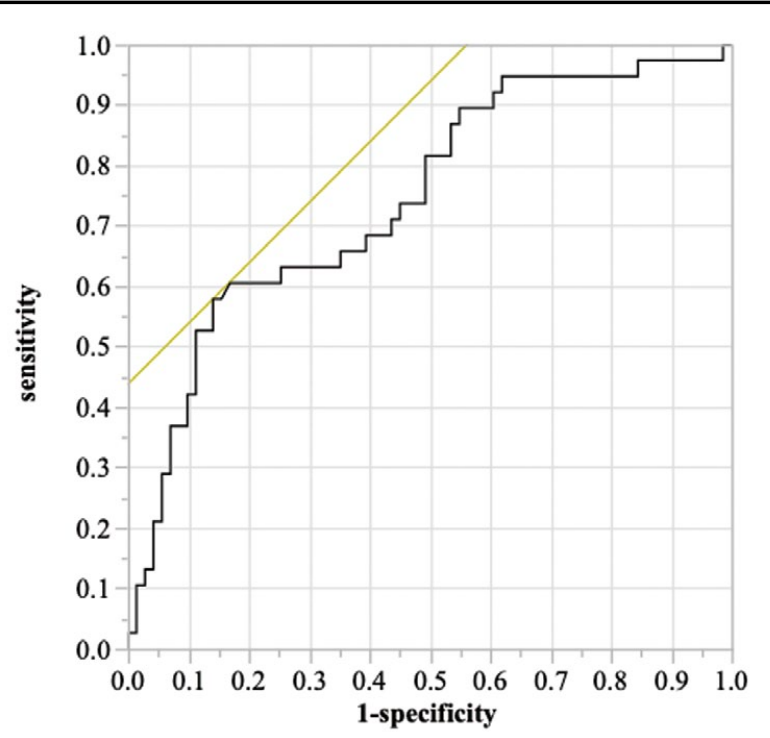

Figure 4. Receiver-operating characteristics curve of the $E$ wave flow during PVC. PVC E wave flow of $8.1 \mathrm{~cm}$ had a sensitivity of $58 \%$ and a specificity of $86 \%$ to differentiate patients with PVC-related symptoms from patients without PVC-related symptoms. PVC, premature ventricular contraction.

PV reversal flow. Those authors investigated the relationship between symptom expressed during supraventricular tachycardia, so-called "neck pounding" and "shirt flapping", and the timing of atrioventricular contraction. They concluded that the symptoms were caused by PV reversal flow resulting from atrial contraction at the time of mitral valve closure. In addition, previous reports have investigated the relationship between transient and sudden pulmonary capillary wedge pressure (PCWP) elevation and symptoms. Thibodeau et $\mathrm{al}^{26}$ described a patient with a significant increase in PCWP in so-called "bendopnea" who developed shortness of breath in the bent forward position compared with asymptomatic patients. They hypothesized that during bending, intrathoracic pressure increased, and the LV filling pressure and PCWP increased, causing symptoms. That finding suggests the possibility of symptoms appearing because of a sudden increase in PCWP caused by PVCs. We excluded patients with cardiac dysfunction, and there was no significant difference in left atrial and left ventricular volumes between the 2 groups. Therefore, the patient group in this study clearly reflected the symptoms and hemodynamic changes with PVCs.

There were no patients who were hospitalized for uncontrollable heart failure or cardiac death during the followup period (mean follow-up period: $14.9 \pm 10.1$ months).

\section{Clinical Implications}

Our findings should be helpful for cardiologists to identify patients who need antiarrhythmic drugs and/or invasive treatment such as cardiac radiofrequency catheter ablation. Long-term PVC morbidity and high frequency PVCs can result in the development of PVC-induced cardiomyopathy. ${ }^{7,27}$ Yokokawa et $\mathrm{al}^{28}$ suggest that asymptomatic PVC patients are at increased risk of developing LV dysfunction. They describe asymptomatic patients as more likely to require medical attention later than symptomatic 
patients; hence asymptomatic PVCs might increase the risk of PVC-induced cardiomyopathy.

In order to prevent progression to cardiomyopathy, it is important to diagnose PVCs as a cause of symptoms at an early stage. However, our research did not suggest how decreased PVC E wave flow directly causes cardiomyopathy, and further research is needed.

\section{Study Limitations}

We excluded 27 patients with structural heart disease because systolic and diastolic function disorders could change the hemodynamics. We also excluded 7 patients with suspected heart failure symptoms, such as dyspnea on exertion, or whose symptomology was unclear. In addition, 44 patients without PVCs recorded on echocardiography were excluded. Therefore, there is a potential selection bias in this study.

Second, we used medical records to determine the presence of symptoms and the study patients were grouped accordingly. Some patients may have adapted to symptoms they were experiencing and hence, there is a possibility they did not complain of them to the doctors initially.

\section{Conclusions}

Decreased E wave flow at the time of PVC was independently related to PVC-related symptoms in patients with PVCs. The LV contraction at the time of inadequate filling might be a cause of PVC-related symptoms.

\section{Conflict of Interest Statement}

The authors have no financial conflicts of interest to disclose.

\section{Funding Sources}

This research did not receive any specific grant from funding agencies in the public, commercial, or not-for-profit sectors.

\section{References}

1. Hiss RG, Lamb LE. Electrocardiographic findings in 122,043 individuals. Circulation 1962; 25: 947-961.

2. Ng GA. Treating patients with ventricular ectopic beats. Heart 2006; 92: $1707-1712$.

3. Lin CY, Chang SL, Lin YJ, Lo LW, Chung FP, Chen YY, et al. Long-term outcome of multiform premature ventricular complexes in structurally normal heart. Int J Cardiol 2015; 180: 80-85.

4. Lin CY, Chang SL, Lin YJ, Lo LW, Chung FP, Chen YY, et al. An observational study on the effect of premature ventricular complex burden on long-term outcome. Medicine 2017; 96: e5476.

5. Lin CY, Chang SL, Chung FP, Chen YY, Lin YJ, Lo LW, et al. Long-term outcome of non-sustained ventricular tachycardia in structurally normal hearts. PLoS One 2016; 11: e0160181.

6. Baman TS, Lange DC, Ilg KJ, Gupta SK, Liu TY, Alguire C, et al. Relationship between burden of premature ventricular complexes and left ventricular function. Heart Rhythm 2010; 7: 865-869.

7. Sadron Blaye-Felice M, Hamon D, Sacher F, Pascale P, Rollin A, Duparc A, et al. Premature ventricular contraction-induced cardiomyopathy: Related clinical and electrophysiologic parameters. Heart Rhythm 2016; 13: 103-110.

8. Del Carpio Munoz F, Syed FF, Noheria A, Cha YM, Friedman PA, Hammill SC, et al. Characteristics of premature ventricular complexes as correlates of reduced left ventricular systolic function: Study of the burden, duration, coupling interval, morphology and site of origin of PVCs. J Cardiovasc Electrophysiol 2011; 22: $791-798$.

9. Hasdemir C, Ulucan C, Yavuzgil O, Yuksel A, Kartal Y, Simsek $\mathrm{E}$, et al. Tachycardia-induced cardiomyopathy in patients with idiopathic ventricular arrhythmias: The incidence, clinical and electrophysiologic characteristics, and the predictors. J Cardiovasc Electrophysiol 2011; 22: 663-668.

10. Murray GL. Ranolazine is an effective and safe treatment of adults with symptomatic premature ventricular contractions due to triggered ectopy. Int J Angiol 2016; 25: 247-251.

11. Hohnloser SH, Meinertz T, Stubbs P, Crijns HJ, Blanc JJ, Rizzon $\mathrm{P}$, et al. Efficacy and safety of d-sotalol, a pure class III antiarrhythmic compound, in patients with symptomatic complex ventricular ectopy: Results of a multicenter, randomized, double-blind, placebo-controlled dose-finding study: The d-Sotalol PVC Study Group. Circulation 1995; 92: 1517-1525.

12. Hyman MC, Mustin D, Supple G, Schaller RD, Santangeli P, Arkles J, et al. Class IC antiarrhythmic drugs for suspected premature ventricular contraction-induced cardiomyopathy. Heart Rhythm 2018; 15: 159-163.

13. Oomen AWGJ, Dekker LRC, Meijer A. Catheter ablation of symptomatic idiopathic ventricular arrhythmias: A five-year single-centre experience. Neth Heart J 2018; 26: 210-216.

14. Stec S, Sikorska A, Zaborska B, Krynski T, Szymot J, Kulakowski $P$. Benign symptomatic premature ventricular complexes: Shortand long-term efficacy of antiarrhythminc drugs and radiofrequency ablation. Kardiol Pol 2012; 70: 351-358.

15. Zhong L, Lee YH, Huang XM, Asirvatham SJ, Shen WK, Friedman PA, et al. Relative efficacy of catheter ablation vs. antiarrhythmic drugs in treating premature ventricular contractions: A single-center retrospective study. Heart Rhythm 2014; 11: $187-193$.

16. Im SI, Kim SH, Kim BJ, Cho LI, Kim HS, Heo JH. Association of frequent premature ventricular complex $>10 \%$ and stroke-like symptoms without a prior diagnosis of stroke or transient ischemic attack. Int J Cardiol Heart Vasc 2018; 19: 58-62.

17. Park KM, Im SI, Chun KJ, Hwang JK, Park SJ, Lim JS, et al. Coupling interval ratio is associated with ventricular premature complex-related symptoms. Korean Circ J 2015; 45: 294-300.

18. Lang RM, Bierig M, Devereux RB, Flachskampf FA, Foster E, Pellikka PA, et al. Recommendations for chamber quantification: A report from the American Society of Echocardiography's Guidelines and Standards Committee and the Chamber Quantification Writing Group, developed in conjunction with the European Association of Echocardiography, a branch of the European Society of Cardiology. J Am Soc Echocardiogr 2005; 18: $1440-1463$

19. Stec S, Tarnowski W, Kalin K, Sikora K, Kulakowski P. Highresolution esophageal manometry with ECG monitoring for management of premature ventricular complexes-associated dysphagia. Dysphagia 2010; 25: 66-69.

20. Stec S, Zaborska B, Pilus A, Lewandowski P, Kulakowski P. Intermittent claudication caused by frequent premature ventricular complexes: Resolution after radiofrequency ablation. Angiology 2009; 60: $378-381$.

21. Lelakowski J, Dreher A, Majewski J, Bednarek J. Effects of catheter ablation of idiopathic ventricular ectopic beats on left ventricular function and exercise capacity. Kardiol Pol 2009; 67: $847-855$.

22. Contijoch F, Rogers K, Rears H, Shahid M, Kellman P, Gorman $\mathrm{J} 3 \mathrm{rd}$, et al. Quantification of left ventricular function with premature ventricular complexes reveals variable hemodynamics. Circ Arrhythm Electrophysiol 2016; 9: e003520.

23. Jin SW, Kim JH, Rho TH, Cho EJ, Kim HY, Lee MY, et al. Hemodynamic change during premature ventricular contraction with different sites of origin and coupling intervals in dogs. Korean Circ J 1999; 29: 697-704.

24. Cohn K, Kryda W. The influence of ectopic beats and tachyarrhythmias on stroke volume and cardiac output. J Electrocardiol 1981; 14: 207-218.

25. Laurent G, Leong-Poi H, Mangat I, Korley V, Pinter A, Hu X, et al. Influence of ventriculoatrial timing on hemodynamics and symptoms during supraventricular tachycardia. $J$ Cardiovasc Electrophysiol 2009; 20: 176-181.

26. Thibodeau JT, Turer AT, Gualano SK, Ayers CR, Velez-Martinez $\mathrm{M}$, Mishkin JD, et al. Characterization of a novel symptom of advanced heart failure: Bendopnea. JACC Heart Fail 2014; 2: 24-31.

27. Hasdemir C, Ulucan C, Yavuzgil O, Yuksel A, Kartal Y, Simsek $\mathrm{E}$, et al. Tachycardia-induced cardiomyopathy in patients with idiopathic ventricular arrhythmias: The incidence, clinical and electrophysiologic characteristics, and the predictors. J Cardiovasc Electrophysiol 2011; 22: 663-668.

28. Yokokawa M, KimHM, Good E, Chugh A, Pelosi F Jr, Alguire $\mathrm{C}$, et al. Relation of symptoms and symptom duration to premature ventricular complex-induced cardiomyopathy. Heart Rhythm 2012; 9: 92-95. 